\title{
Gender Dimensions of Poverty and Coping Options among Smallholder Farmers in Eastern Nigeria
}

\author{
Isaac B. Oluwatayo, PhD \\ Department of Agricultural Economics and Animal Production, University of Limpopo, Sovenga 0727, South Africa \\ Email: isaac.oluwatayo@ul.ac.za
}

\section{Doi:10.5901/mjss.2014.v5n27p49}

\section{Abstract}

The study examines gender dimensions of poverty and the coping options among smallholder farmers in Eastern Nigeria. Primary data used in this study were collected through interview schedule a well-structured questionnaire administered on 199 respondents using a multistage random sampling technique. Seven major autonomous communities were covered in the survey. Analytical tools employed include simple descriptive statistics, probit model and the coping strategies use index (CSUI) generated based on the information gathered from respondents. The result of descriptive analysis shows that there were more female respondents (56.3\%) than the male respondents (43.7\%) in the study area. Most of the households were headed by male respondents (71\%) as compared to the female respondents (29\%). More women also had their major occupation as farming (56\%) than the men (42\%), with more men (13.8\%) having tertiary level of education than the women (10.2\%). Also, more female respondents were poor (43.7\%) as compared to their male counterparts (33.3\%). The results of the probit analysis shows that age, gender, level of education, major occupation, household size, amount of remittances received and extension services had significant effect on the poverty status of the respondents. Meanwhile, of the 11 coping strategies available in the study area, the study shows that relying on less expensive clothes which had a percentage of 11.2 was the widely used option by majority of the respondents. This is closely followed by spending of savings, reduction of in diversity of dietary intake, reduction in the number of meals taken per day and reduction of the quantity of food consumed respectively. The respective percentages of these strategies are 10.5, 10.2, 10.2, and 10.1. It is therefore recommended that improvement in human capacity building through investment in education should be priotized. Also, policies made to assist smallholder famers in the study area should be gender-mainstreamed.

Keywords: Coping strategies, Eastern Nigeria, Gender, Poverty, Smallholder farmers

\section{Background of the Study}

There is a debate on the relationship between smallholder famers and the poverty level in sub- Saharan Africa (Spencer 2002; Poulton et al 2005; Lipton 2005). Evidence from previous studies have also shown that sub-Saharan Africa is the poorest region in Africa and they depend highly on agriculture as the primary source of food and income ( Ayoola et al, 2000; Okunmadewa, 2002; Alayande and Alayande, 2004). Poverty is a largely rural phenomenon and tends to be deeper than the urban poverty (Apata et al 2010). In Nigeria rural poverty is relatively high and this is based on a national poverty survey carried out which indicates that the high tropic areas have moderate poverty while the while the northern regions have a high level poverty which is as high as 60\% (Apata and Apata 2010; Okunmadewa et al, 2005; NBS, 2009). Poverty has a dynamic nature; this is so because some people or some households experience poverty for a very long period of time than others while others experience it on temporary basis due to incidence of shock and uncertainties which result to a loss of welfare and income.

Gender on the other hand focuses on the different roles and responsibilities of women and men and how these affect the society, culture, the economy and politics. For example, important differences exist between women and men in their quality of life; in the amount, kind and recognition of work they do; in health and literacy levels; and in their economic, political and social standing. Women are too often marginalized in their families and their communities, suffering from lack of access to credit, land, education, decision-making power and rights to work. Not surprisingly, women therefore comprise the majority of the world's poor in both the urban and rural sectors and the majority of those working in the informal sector (Spieldoch, 2007).

The interest in analyzing the phenomenon of poverty from a gender perspective is based on the need to recognize that poverty affects men and women in different ways and is possible to identify the gender factors that increase or decrease the probability of individuals experiencing poverty, and how the characteristics of poverty are different for men 
and women. Moreover, a gender perspective enhances the understanding of poverty because it goes beyond a descriptive analysis to also look at the causes of poverty. It approaches poverty as a process, and so it gives a more dynamic perspective. In addition, a gender perspective contributes to policy making allowing measures to be directed at the poorest of the poor and to the most vulnerable populations (IFAD, 2009).

The 'feminization of poverty' is a feature of much of the developing world, with females accounting for half of the world's population but 70 percent of the poor (Moghadam, 2005). There are significant differences in the condition of different groups of women in the various parts of the country. However, they share a common predicament, rooted in the interaction of three major factors: weak governance, traditional restrictions on women property rights, and violent civil conflict. Although each of these factors has been present at one time or another elsewhere, it is only in sub-Saharan Africa (Nigeria inclusive) that all the three have been present in contemporary times as shown among others by Collier (2009) and Cornwall (2005). This interaction has had a severe negative impact on the status, condition and welfare of women in sub-Saharan Africa.

According to Abumere and Oluwasola (2001) there are probably as many definitions of poverty as there are researchers in the field. These varied definitions can be grouped into three broad categories that define poverty in terms of income, consumption and access to social and physical infrastructure. Abumere and Oluwasola (2001) further stressed that poverty as a multi-component phenomenon cannot be defined or measured by one single variable like income but must be defined in terms of many other variables such as consumption, socio-economic resources, access to social and political infrastructure and demographic variables such as life expectancy and infant mortality, political participation, freedom and human rights.

However, smallholder farmers are those farmers who do not produce agricultural products on a large scale. They produce in small quantities usually for the consumption of their families and then the little excess remaining they bring them to the market. Some also produce just for the market but on a small scale. Most of the farmers in Nigeria operate on a small scale and a few on medium scale with both men and women found in these categories. Meanwhile, the female smallholder farmers which include the female agro-pastoralists are the ones who are involved in planting, weeding, food cropping, milking (livestock), petty trading, and taking farm products to the market for sale, child care, and general house management (Obisesan, 2013).

Worse still, these female smallholder farmers are still constrained with many factors which serve as a risk to their source of livelihood. In Eastern Nigeria, for instance, women are not allowed to make decisions about land and property, their voices are not heard in meetings and gatherings that concern their development (Ike and Oboh, 2009). Thus, female farmers are faced with the problem of gender inequality whereby they are not allowed to attend local meetings with the men where decisions are made concerning the socioeconomic attributes of their life. Their voices are not heard, their problems are not attended to, except for the problems which the men decide to find a solution to.

\section{Literature Review}

Poverty is much more than just low income level. It goes beyond this simple concept, and indicates poor health and education, knowledge deprivation and communication, inability to exercise human and political rights and the absence of dignity, confidence and self-respect. Using monetary income or consumption to identify and measure poverty has been a long term tradition. Most quantitative poverty analysis is based on household income and expenditure surveys and the approach has become important for policy makers. This is because it is based on nationally representative samples and it allows inferences about the conditions and evolution of poverty at the national level. Moreover, since household surveys collect information beyond monetary income or consumption, the approach makes it possible to obtain a broader picture of well-being and poverty, so as to investigate the relationships among different dimensions of poverty, and to test hypotheses on the likely impact of policy interventions.

Poverty is a multi-dimensional phenomenon that affects many aspects of human conditions ranging from the physical, moral to psychological. It is defined as the state of being poor or deficient in money or means of subsistence. The concept of basic subsistence can be measured by the availability of infrastructural services such as safe water, sanitation, solid waste collection, health care, schools and security. Poverty can also be defined based on the concept of lack of access to opportunities and resources, concern for human rights and environmental challenges. Other factors include exposure to violence, injustice, powerlessness and uncertainty in the face of unexpected situations like sicknesses, accidents and natural disasters (Agbi, 2009).

Thus, there are other factors determining the standard of living and affecting welfare that cannot be readily reduced to a single monetary measure. Examples of such factors are access to education, access to basic health services, and access to safe potable water and basic housing amenities. The basic needs approach becomes particularly suited for 
measuring poverty in developing countries, since it bases poverty comparisons in the deprivation from certain commodities and resources (both food and non-food) that are deemed essential to afford a minimum level of well-being within a given society. This can mean the inability of individuals to attain adequate or minimum nutrition, clothing, or shelter; or more broadly, it encompasses those factors that enable the command of individuals over resources, such as being healthy and literate (El-laith, 2008).

A nation's standard of living is determined, among other things; by the economic condition of the nation and the productivity of her citizens the quantity of the goods and services that a worker can produce for each hour of work. A country may prosper if her citizens (both male and female) are productive and do not possess much anti-growth behaviour such as corruption, bad work ethics and gender inequality. The mention of work ethic and gender inequality takes us to the issue of "culture," which is a significant determinant of a nation's ability to prosper, which shapes individuals' thoughts about risk, reward and opportunity, whereby both, men and women are treated fairly and equally at their various jobs and workplaces. (Mujer Desarollo, 2004). The labour utilization in agricultural activities are diverse but gender inequality exists in wage remunerations by tasks and gender. There is a strong indication of gender inequality in decision making, and where the decision is made it is mostly by the widow and not the married or single women (Rahman, 2008).

Nigerian agriculture is dominated by the smallholder farmers who produce the bulk of food in the country. Despite their unique position, the small holder farmers belong to the poorest segment of the population and therefore, they cannot invest much on their farms (Federal Republic of Nigeria - FGN, 2007; Asogwa, 2012). The vicious circle of poverty among these farmers has led to the unimpressive performance of the agricultural sector. According to Ajibefun (2002), there is crucial need to raise agricultural growth as such growth is the most efficient means of alleviating poverty. For Nigeria, raising productivity per area of land is the key to effectively addressing the challenges of achieving food security, as most cultivable land has already been brought under cultivation, and in areas where wide expanse of cultivable land is still available, physical and technological constraints which are due to poverty, prevent large-scale conversion of potentially cultivable land.

Poor households are more in agricultural occupation (62\%) than in non-agricultural occupation (54\%). The gap in poverty level of farm households and non-farm households stood at $9 \%$. About $56 \%$ of farmers living in the urban areas were poor, while about $63 \%$ of those in the rural areas were poor (FGN, 2005). For many households in Nigeria, especially in the rural areas, agriculture is the main activity, and previous and current analysis of poverty has shown that poverty is disproportionately concentrated among households whose primary livelihood lie in agricultural activities (FGN, 2007). Agriculture has been focused as a central element of poverty reduction strategy in Nigeria (FGN, 2005, 2007; Asogwa, 2012).

\subsection{Gender Perspective of Poverty}

The term "feminization of poverty" originated in the United States in the late 1970s, when it was discovered that the fastest growing type of family structure was that of female-headed households. Moreover, because of the high rate of poverty among these households, their increase was mirrored in the growing numbers of women and children who were poor. By the mid-1980s, it was believed that almost half of all the poor in the U.S. lived in families headed by women in various stages of the life-cycle (Mahogadam, 2005; Medeiros and Costa, 2008).

The feminization of poverty is a phenomenon that is said to exist if poverty is more prevalent among females than men and the reasons for the existence of feminized poverty could be attributed to discrimination against women in the labour market or that women tend to have lower education than men and are therefore paid lower salaries. Also when markets undergo changes the issue of feminized poverty gets higher and increases gender inequalities (Anyanwu, 2010). The feminist approach to poverty focuses on the gender implications and social costs of poverty. They include the growing involvement of women and children in the informal economy; differential treatment of girls and boys in households; pressure to get girls married off quickly; higher school drop-out rates for girls; less control over fertility; and recourse to prostitution (Mahogadam, 2005) Feminist approaches to women's poverty begin with the premise that pervasive gender inequalities and biases within households, labor markets, legal codes, and political systems throughout the world, render women more vulnerable than men to poverty (Mahogadam, 2005).

The term 'feminization of agriculture' can mean different things and should be used with care. It refers broadly to women's increasing presence (or visibility) in the agricultural labour force, whether as agricultural wage workers, independent producers or unremunerated family workers. Others use the term to indicate deterioration in the quality of agricultural work. Evidently, the forms and conditions under which women are incorporated in agricultural employment matter for gender equality and poverty outcomes - feminization of casual agricultural labour is not the same as 
feminization of farm management. It also matters whether an increase in the share of women in the agricultural labour force relative to men is because more women are becoming economically active in agriculture or because fewer men are working in the sector.

Extra caution should also be used in interpreting higher rural female participation rates as true 'feminization', as these higher rates may be simply a reflection of women's contribution to agriculture starting to be better counted in standard statistics. The evidence is patchy and anecdotal in most countries and regions. Statistics over time are rarely available, making the task of answering this question even harder (Fontana and Paciello, 2010).

Gender analysis focuses on the different roles and responsibilities of women and men and how these affect society, culture, the economy and politics. For example, important differences exist between women and men in their quality of life; in the amount, kind and recognition of work they do; in health and literacy levels; and in their economic, political and social standing. Women are too often marginalized in their families and their communities, suffering from a lack of access to credit, land, education, decision-making power and rights to work (Spleidoch, 2007; Ajani,2008).

Inequities in access to and control of assets have severe consequences for women's ability to provide food, care, health, and sanitation services to themselves, their husbands, and their children, especially their female children. In the African context, female children have double tragedy of coincidence; first, they are least preferred in the household because of their gender in the provision of food, care, health, etc, and secondly, when they grow up to be adults they have to deny self in order to make these earlier mentioned provisions for their family members (Akinsanmi et al., 2005). Women with less influence or power within the household and community are unable to guarantee the fair distribution of food within the household. These women also have less ability to visit health clinics when their infants and children are sick.

Gender inequalities between men and women in accessing and controlling resources is not only unfair to women and their children, but also constitutes bad economics, resulting in the misallocation of scarce resources, increased healthcare costs, lowered productivity, and poor human development trends. Investment in the nutrition of women is an important short-term barometer in assessing expected returns to improving household nutrition and overall human development capacity for a country (Oniang'O and Mukudi, 2002).

\section{Methodology}

\subsection{Study Area}

This study was carried out in Umuahia South local government area of Abia State, which is located in the south eastern part of Nigeria. Abia State was created in August 27, 1991 from part of Imo State and it is one of the nine constituent states of Niger Delta region. The geographical coordinates of Abia State is $5^{\circ} 25^{\prime} \mathrm{N} 70^{\circ} 30^{\prime} \mathrm{E}$. The capital of Abia State is Umuahia. The name 'Abia' is an abbreviation of four of the state's densely populated regions, namely; Aba, Bende, Isikwuato and Afikpo. Abia State has 17 local government areas where Umuahia South local government area.

Umuahia south local government area has its headquarters in Apumuri with various autonomous communities. The citizens are predominantly lgbo people and the major language is lgbo language. The citizens are also predominantly Christians and English is the widely spoken official language. It has an area of $140 \mathrm{~km}^{2}$ and a population of 138,570 at the 2006 census. The major occupations of the people are farming, petty trading, transportation, and non-farming activities such as food processing, vocational jobs and other forms of businesses.

\subsection{Data Sources and Sampling Technique}

The data used for this study is a primary data. The data was collected with the use of a well-structured questionnaire and an in-depth interview that was administered to the respondents. The questionnaire was designed to provide information on the coping options used by the female farmers in the area of study and some personal data of the respondents. Some of the information sought by the questionnaire and interview includes: Socioeconomic/Demographic data: age of respondents, sex of respondent, household size, years of formal education, occupation, yearly income of respondents, expenditure of respondents yearly, quantity of food consumed on a weekly, monthly and yearly basis. Data were collected on the quantity of food purchased, price of food purchased, quantity of food produced from the farm, quantity of food saved per month. Data were also collected on poverty coping strategies employed by the respondents.

However, a multi-stage sampling technique was used. The first stage is the use of purposive sampling to select Umuahia South Local Government Area (LGA) and the reason for picking this LGA is because every household living in this area has a farmland and so a sizeable number of the inhabitants are farmers. Another reason is that the local custom 
of the people in this area has a very high impact on their lifestyle and most especially on their agricultural systems. The second stage is the random sampling technique whereby some autonomous communities were picked and the third stage was the random selection of respondents interviewed.

\subsection{Analytical techniques}

This study employed various analytical tools to analyze both quantitative and qualitative data collected. The analytical tools used were based on the objectives of this study as stated earlier. The tools used include:

\subsubsection{Descriptive Statistics}

The simple tool used includes tables, frequencies and percentage frequencies these were used to catalogue and categories respondents using socioeconomic and demographic variables.

\subsubsection{Poverty Measure}

This was done by categorising respondents into poor and non poor groups using the two-third mean per-capita expenditure (World Bank, 1986) as the benchmark. Respondents whose mean expenditure falls below the poverty line are considered poor while those whose mean expenditure is above the above the poverty line is considered not poor.

Per-capita Expenditure (PERCAPEX)= Expenditure of the respondents

Total Expenditure (TOTEXP) = summation of Per-Capita Expenditure (PERCAPEX)

Mean Total Expenditure (TOTEXP) $=$ TOTEXP/total number of respondents $=$ MTOTEXP

Poverty Line $(\mathrm{PL})=2 / 3$ * MTOTEXP

\subsubsection{Probit Regression Model}

The probit model was used to examine the determinants of poverty among male and female farmers. A poverty line was used to categorise the respondents into poor and non-poor groups, therefore respondents whose per-capita expenditure (PERCAPEX) was below the poverty line are considered poor while the respondents whose per-capita expenditure (PRECAPEX) were above poverty line are considered non poor. Thus the regressand takes the values of 0 and 1 which implies poor and non-poor respectively. Also the socio-economic characteristics of the respondents were used as the independent variable while poverty was used as the dependent variable.

The probit model is a model used in estimating the probability of events based on dichotomous dependent variable. (O'Hallorous 1999). A dichotomous dependent variable is a variable that assumes only two values either zero or one.

Assuming poverty line is represented as $\mathrm{PL}$, where $\mathrm{PL}$ is 0 if the respondent is poor and $\mathrm{PL}$ is 1 when the respondent is non-poor. The probit model will be given as:

$\operatorname{PPL}\left(Y_{i t}=1\right)=\exp \left(\beta_{P L} . Z_{i t}\right) P_{P L}\left(Y_{i t}=0\right)=1-P_{P L}\left(Y_{i t}=1\right)=1$

$1+\exp \left(\beta_{\mathrm{PL} .} Z_{\mathrm{it}}\right) 1+\exp \left(\beta_{\mathrm{PL}} . Z_{\mathrm{it}}\right)$

Where $Y_{i t}=$ dependent variable which takes the value of 0 if the ith respondent is poor and 1 otherwise.

$\beta$ is the vector of unknown coefficients

$Z_{i t}$ is the vector of explanatory variables related to the ith respondents.

While the explanatory variable are:

$X_{1}=$ age of respondents (years)

$X_{2}=$ gender (male $=0$, female $=1$ )

$X_{3}=$ marital status $(0=$ single, widowed or divorced $1=$ married $)$

$X_{4}=$ level of education ( $0=$ no formal education, $1=$ have formal education)

$X_{5}=$ household size

$X_{6}=$ major occupation (farm $=1$ non-farm $=0$ )

$\mathrm{X}_{7}=$ savings (yes $=1$ no $=0$ )

$X_{8}=$ amount received as remittances (Naira)

$X_{9}=$ extension contact (yes $=1,0$ otherwise 


\subsubsection{Coping Strategies Use Index (CSUI)}

This was employed in order to access the extent to which the coping strategies were used by the respondents. The knowledge of this allows us to have a better and clearer understanding of the possible strategies in which the respondents have been applying in order to improve their living standards and reduce poverty.

In analyzing the extent of use of any of the coping strategies by the respondents in the study area, a coping strategy index (CSI) was developed by ranking. The extent of use of the coping strategy index was expressed using a four-point scale with the scoring order 3, 2, 1 and 0 which represents always used, sometimes used, rarely used and never used respectively. The formula used to obtain the coping strategy index was adopted by Oluwatayo (2005) where he estimated the gender considerations in decision making in rural areas: implications on household food security in Ekiti State. The formula was used to obtain the coping strategy index (CSI) as:

$\mathrm{CSUI}=\mathrm{N}_{1} \mathrm{X}_{3}+\mathrm{N}_{2} \mathrm{X}_{2}+\mathrm{N}_{3} \mathrm{X}_{1}+\mathrm{N}_{4} \mathrm{X}_{0}$

Where:

CSUI = coping strategy use index

$\mathrm{N}_{1}=$ number of respondents using a particular CSI always

$\mathrm{N}_{2}=$ number of respondents using a particular CSI sometimes

$\mathrm{N}_{3}=$ number of respondents using a particular CSI rarely

$\mathrm{N}_{4}=$ number of respondents that not using any of the CSI

The CSUI was used a ranking order to show the relative position of each of the CSI in terms of their use. The extent of use of the CSI was then obtained for all the respondents in the study area.

\section{Results and Discussion}

\subsection{Demographic and Socioeconomic Characteristics of Respondents}

Demographic characteristics of respondents considered include age, gender, marital status, level of education, household size and major occupation.

\subsubsection{Age of Respondents}

The average age of respondents is 51years and this shows that majority of the respondents are still in their active stage and can perform farm activities efficiently. A large number of the respondents fell between 39-48 years of age constituting about $29.20 \%$ of them. This age range is where the respondents are still very active on the farm. Respondents falling between 19-28 years of age constitute about 7.53\%. Respondents with age ranging from 69 to 79 years constitute $9 \%$ of the total population of the respondents. The reason is that at this age most of them are too weak to work on the farm, they can no longer perform most of the activities on the farm and so the men hand over their farmlands to their sons. Average age of the female respondents was 50.8 years and this implies that of the women in the study are still in their active age and can still perform a lot of farm and non-farm activities. Most of the female respondents fell within the age range of 39 and 48 years constituting the highest percentage which is $29.2 \%$ and they were still active and young. At this age range most of the women are still very strong and are willing to compete with their fellow women to see who gets the highest yield of farm produce. Also the women at this stage have responsibilities and children to take care of so they have to work hard on the farm to be able to have money to buy food for the family.

Table 1: Distribution of Age of Respondents

\begin{tabular}{|c|c|c|c|c|}
\hline \multirow{2}{*}{ Age } & \multicolumn{2}{|c|}{ Frequency } & \multicolumn{2}{|c|}{ Percentage } \\
\cline { 2 - 5 } & Male & Female & Male & Female \\
\hline$<30$ & 7 & 7 & 8.0 & 6.3 \\
$31-40$ & 12 & 20 & 13.8 & 17.9 \\
$41-50$ & 21 & 27 & 24.1 & 24.1 \\
$51-60$ & 20 & 34 & 23.0 & 30.4 \\
$>60$ & 27 & 24 & 31.0 & 21.4 \\
\hline Total & 87 & 112 & 100 & 100 \\
\hline
\end{tabular}

Source of Data: Field survey. 


\subsubsection{Gender of Respondents}

A larger percentage of those interviewed were women constituting $56.3 \%$ of the total population of the respondents while the male respondents were $43.7 \%$.. This could be because most of the farm activities in the study area are handled by women and this is substantiated by the study conducted by Chianu and Tsuji (2004) on the influence of gender on labour allocation in agricultural production in the savannah region of Northern Nigeria. His results showed a positive correlation in labour allocation between mothers and female children in crop production and processing and a medium positive correlation between fathers and male children in processing and livestock production.

Table 2: Gender Distribution of Respondents

\begin{tabular}{|c|c|c|}
\hline Gender & Frequency & Percentage Distribution (\%) \\
\hline Male & 87 & 43.7 \\
Female & 112 & 56.3 \\
\hline Total & 199 & 100 \\
\hline
\end{tabular}

Source of Data: Field survey.

\subsubsection{Marital Status of Respondents}

Majority of the respondents were married and they constituted about $69.8 \%$ of the total number of the respondents and only about $5.0 \%$ were single, $23.1 \%$ were widowed and $2.0 \%$ were divorced. This could be due to rural-urban migration whereby the youths who are not married have migrated to urban areas leaving the elderly ones in the village to farm, while some of them especially the women are widowed. This could be due to the age differences between the men and women and men tend to die earlier than the women. Research by Akinsanmi et al (2005) has shown that the females have better health than the men which could also be a reason for the death of the husbands leaving the women as widows. The rate of divorce is very low according to the data below and this could be because of the long cultural procedure it takes before divorce can take place.

Table 3: Distribution of the Marital Status of the Respondents

\begin{tabular}{|c|c|c|}
\hline Marital Status & Frequency & Percentage Distribution (\%) \\
\hline Single & 110 & 5.0 \\
Married & 139 & 69.8 \\
Widowed & 46 & 23.1 \\
Divorced & 4 & 2.0 \\
\hline Total & 199 & 100 \\
\hline
\end{tabular}

Source of Data: Field survey.

\subsubsection{Household Head of the Respondents}

The result in Table 4 shows that most of the households of respondents were headed by the men. Male-headed households constituted about $71.0 \%$ while $29.0 \%$ of the households were headed by women. Out of the households headed by women, most of them are usually widows with very few divorcees, as divorce is a very rare occurrence in the culture of Eastern Nigeria.

Table 4: Distribution of Respondents by Household Heads

\begin{tabular}{|c|c|c|}
\hline Household Head & Frequency & Percentage Distribution (\%) \\
\hline Male & 142 & 71.0 \\
Female & 57 & 29.0 \\
\hline Total & 199 & 100 \\
\hline
\end{tabular}

Source of Data: Field survey. 


\subsubsection{Educational Level of Respondent}

Most of the respondents interviewed had no formal education and constituted $38.2 \%$ of the total population of the respondents. Only $5.5 \%$ of the total number of respondents attained the tertiary level of education. Most of the female respondents have only secondary level of education and the respondents in this category constitutes about $42.9 \%$. The level of education of the male respondents is more widely spread among the different levels of education. A good percentage of the male respondents got to the tertiary level of education unlike the female respondents whereby they constitute $19.5 \%$ of the total population of the male respondents whereas only $10.7 \%$ of the total female population attained the tertiary level of education and this implies that men have easier access to better education than women and this also corresponds to the research done by Okorie (2013).

Table 5: Distribution of Respondents' Educational Status

\begin{tabular}{|c|c|c|}
\hline Educational Attainment & Frequency & Percentage Distribution (\%) \\
\hline Primary Education & 76 & 38.2 \\
Secondary Education & 75 & 37.7 \\
Tertiary Education & 37 & 18.6 \\
No Formal Education & 11 & 5.5 \\
\hline Total & 199 & 100 \\
\hline
\end{tabular}

Table 6: Distribution of respondents' educational status by their gender

\begin{tabular}{|c|c|c|c|c|}
\hline \multirow{2}{*}{ Level of education } & \multicolumn{2}{|c|}{ Frequency } & \multicolumn{2}{c|}{ Percentage } \\
\cline { 2 - 5 } & Male & Female & Male & Female \\
\hline Primary Education & 25 & 40 & 28.7 & 35.7 \\
Secondary Education & 33 & 48 & 37.9 & 42.9 \\
Tertiary Education & 17 & 12 & 19.5 & 10.7 \\
No Formal Education & 12 & 12 & 13.8 & 10.7 \\
\hline Total & 87 & 112 & 100 & 100 \\
\hline
\end{tabular}

Source of Data: Field survey.

\subsubsection{Poverty Status of Respondents}

The male respondents that are poor constitute about $66.7 \%$ of the total population of the male respondents while the female respondents that are poor constitutes about $56.3 \%$ of the total population of the female respondents. This implies that a larger percentage of the men are poor as compared to the percentage of the women. This could be due to the responsibilities bestowed on the men, they are the ones who provide money for the running of the household and most of them have a lot of children. They are also in charge of the school fees of the children and the payment of other basic amenities of the household. The women most of the time go to the farm and bring food home from the farm whereas the man provides money. This high level of responsibility on the man will run affect his poverty status negatively.

In households that are headed by men, the percentage of those that are poor is lower than the percentage of the households that are not poor. The poor households constituted $33.1 \%$ and the percentage of the households that are not poor constituted $66.9 \%$ of the total male respondents. In the distribution of the households headed by females has a reversed case, the percentage of the households headed by females that were poor was quite higher than those that were not poor. The percentage of households headed by poor women constituted $54.4 \%$ of the total number of the female respondents while the households that were not poor constituted $45.6 \%$ of the total population of the female respondents. Therefore this result can indicate that households that are headed female respondents are poorer than households headed by make respondents. This finding corresponds with the findings by Ukoha (2010). This could be because of the difficulty in access to land and other resources that are necessary for agriculture which in turn provide food and income for the families and improve their living standards. The men have more say in landed properties in this study area and this is due to the patriarchal system of inheritance which gives men more and easier access to land for and other major resources. This result corresponds with research performed by Anyanwu (2010) on poverty and gender. 
Table 7: Distribution of Poverty Status of Respondents by Gender

\begin{tabular}{|c|c|c|c|c|}
\hline \multirow{2}{*}{ Poverty status } & \multicolumn{2}{|c|}{ Frequency } & \multicolumn{2}{c|}{ Percentage } \\
\cline { 2 - 5 } & Male & Female & Male & Female \\
\hline Non Poor & 58 & 63 & 66.7 & 56.7 \\
Poor & 29 & 49 & 33.3 & 43.7 \\
\hline Total & 87 & 112 & 100 & 100 \\
\hline
\end{tabular}

Table 8: Distribution of Poverty Status of Respondents

\begin{tabular}{|c|c|c|c|c|}
\hline \multirow{2}{*}{ Poverty status } & \multicolumn{2}{|c|}{ Frequency } & \multicolumn{2}{c|}{ Percentage } \\
\cline { 2 - 5 } & Male & Female & Male & Female \\
\hline Non Poor & 95 & 26 & 66.9 & 45.6 \\
Poor & 47 & 31 & 33.1 & 54.4 \\
\hline Total & 142 & 57 & 100 & 100 \\
\hline
\end{tabular}

Source of Data: Field survey.

\subsubsection{Primary Occupation of Respondents}

Major occupation of the respondents was shared between farmers and non farmers. Most of the female respondents had farming as their major occupation and constituted $50 \%$ of those surveyed whereas fewer male respondents had farming as their major occupation with a percentage of $48.3 \%$. This also implies that most of the male respondents have farming as their secondary occupation while half of the population of the female respondents has farming as their major occupation. This indicates that women engage more in farm activities than the men to provide food for the family. This could be because most men have other occupations to compliment the farm activities in order to raise their income level and provide for their family. These findings corroborated the research conducted by Chikaire et al (2010).

Table 9: Distribution of Respondents' Primary Occupation by Gender

\begin{tabular}{|c|c|c|c|c|}
\hline \multirow{2}{*}{ Major occupation } & \multicolumn{2}{|c|}{ Frequency } & \multicolumn{2}{c|}{ Percentage } \\
\cline { 2 - 5 } & Male & Female & Male & Female \\
\hline Non Farmers & 45 & 56 & 51.7 & 50.0 \\
Farmers & 42 & 56 & 48.3 & 50.0 \\
\hline Total & 87 & 112 & 100 & 100 \\
\hline
\end{tabular}

Source of Data: Field survey.

\subsection{Determinants of Poverty in the Study Area}

In explaining the determinants of poverty in the study area, the regressand which is the poverty index was regressed against a number of socioeconomic variables such as age, gender, marital status, years of education, household size, major occupation (farmers and non-farmers), savings amount received and extension services using a probit model. The result of the analysis is shown in table 15 indicates that age, gender, marital status, and household size and are positively related to the poverty status of the respondents. This also means that increase in any of these variables is associated with likelihood of an increase in the value of the regressand, for instance, as the household size of the respondents' increases there will be a direct increase in the poverty status of the respondents. This is because when there many people in a household, the amount of income and food provided by the household head will not be enough for the household and this will increase their poverty status. Also as the age of the respondents increases, they will not be as active as he used to be in their jobs and in performing farm activities. However, the other socioeconomic variables such as years of education, major occupation and extension services have a negative relationship with the poverty status of the respondents. This also implies that an increase of any the variable is associated with likelihood of decrease in the poverty status of the respondents. For instance, an increase in the extension services rendered to the respondents there will be a decrease in the poverty status of the respondents.

The coefficients of age, years of education, household size, major occupation, amount of remittances received and 
extension services are significant at $1 \%$, while gender is significant at $5 \%$. However, marital status and savings are not significant to the regressand (poverty status of the respondents).

Based on the above results, it can be said that the results generally reveal that the socioeconomic variables, age, gender, years of education, household size, major occupation, amount of income received and extension services are major determinants of the poverty status of the respondents in the study area.

Table 10: Probit Results Showing the Determinants of Poverty in the Study Area

\begin{tabular}{|c|c|}
\hline Variables & Standard Error \\
\hline$X_{1}$ & $0.005^{\star \star}$ \\
$X_{2}$ & $(0.041)$ \\
& $0.138^{\star}$ \\
$X_{3}$ & $(0.334)$ \\
& 0.156 \\
$X_{4}$ & $(0.132)$ \\
& $0.015^{\star \star}$ \\
$X_{5}$ & $(-0.061)$ \\
$X_{6}$ & $0.025^{\star \star}$ \\
& $(0.113)$ \\
$X_{7}$ & $0.150^{\star \star}$ \\
& $(-0.579)$ \\
$X_{8}$ & 0.433 \\
$X_{9}$ & $(-0.263)$ \\
& 0.007 \\
Constant & $(0.00)$ \\
& $0.306^{\star \star}$ \\
& $(-1.787)$ \\
& $0.396^{\star \star}$ \\
\hline
\end{tabular}

Number of observations $=199$

Log likelihood $=-80.200$

Standard error in parenthesis

${ }^{*}$ Coefficient significant at $5 \%$

${ }^{*}$ Coefficient significant at $1 \%$

Source of Data: Field survey.

\subsection{Ranking of Poverty Coping Strategies Used by Respondents Based On Frequency of Use}

The ranking of poverty coping strategies was done by using a four point scale to score the responses of the respondents and the scores are 3, 2, 1 and 0 which indicates always used, sometimes used, rarely used and never used respectively. About 11 strategies were prominent among the available strategies employed. The study shows that of all the informal strategies employed, relying on less expensive clothes which had a percentage of 11.2 was widely used by majority of the respondents in the study area. This is immediately followed by spending of savings, reduction of food diversification, reduction of the number of meals taken per day and reduction of the quantity of food consumed respectively. The respective percentages of these strategies are 10.5, 10.2, 10.2, and 10.1 respectively. Meanwhile the least used of all the coping strategies is relocating to other places which has a percentage of 1.3. The overall study however indicates that the respondents in this study area have adopted various strategies to reduce poverty and have a better livelihood. 
Table 11: Ranking of Poverty Coping Strategies Based on Frequency of Use

\begin{tabular}{|l|c|c|c|c|c|c|c|}
\hline Coping strategies & $\begin{array}{c}\text { Never } \\
\text { used (0) }\end{array}$ & $\begin{array}{c}\text { Rarely } \\
\text { used (1) }\end{array}$ & $\begin{array}{c}\text { Sometimes } \\
\text { used (2) }\end{array}$ & $\begin{array}{c}\text { Always } \\
\text { used (3) }\end{array}$ & CSUI & $\begin{array}{c}\text { \% of } \\
\text { household }\end{array}$ & Rank \\
\hline Reduce the quantity of food consumed. & 13 & 9 & 85 & 92 & 455 & 10.1 & 5 \\
\hline Reduce food diversification. & 14 & 11 & 71 & 103 & 462 & 10.2 & 3 \\
\hline Reduce the number of meals taken per day. & 12 & 11 & 80 & 96 & 459 & 10.2 & 3 \\
\hline $\begin{array}{l}\text { Intensify the amount of work done on the farm to } \\
\text { increase output. }\end{array}$ & 16 & 8 & 80 & 95 & 453 & 10 & 6 \\
\hline Sales of livestock to increase income & 26 & 10 & 73 & 90 & 426 & 9.4 & 8 \\
\hline Diversify off-farm activities to increase income & 34 & 25 & 58 & 82 & 387 & 8.6 & 10 \\
\hline Spending of savings & 14 & 5 & 71 & 109 & 474 & 10.5 & 2 \\
\hline Rely less on expensive clothes & 16 & 4 & 33 & 146 & 508 & 11.2 & 1 \\
\hline Borrow money for the household upkeep & 21 & 18 & 66 & 94 & 432 & 9.6 & 7 \\
\hline Relocate to other places. & 166 & 9 & 22 & 1 & 56 & 1.3 & 11 \\
\hline Purchase items on credit. & 15 & 21 & 103 & 59 & 404 & 8.9 & 9 \\
\hline Total & & & & & 4516 & 100 & \\
\hline
\end{tabular}

Source of Data: Field survey.

\section{Summary, Conclusion and Recommendations}

\subsection{Summary of Findings}

The study examines the gender dimensions of poverty and the coping options among small holder farmers. Primary data was used to obtain the needed information. Socio economic characteristics like gender, age, marital status, level of education, household size, and major occupation were examined.

The findings of this study revealed that more women were involved in agricultural activities than the men. The men have certain crops and farm activities that were attributed to them and an example of the crops attributed to the men is yam planting and harvesting and so this maybe a reason why most of the farm activities are carried out by the women. It was also found that the women were disadvantaged in resource ownership and accessibility to good education. More men attained higher level of education than the women. Most of the women stopped their education in primary and secondary level with very few attaining the tertiary level. This could be because of the belief that exists in the society that education is not necessary for women as their duty is to bear children and run the home. Also the belief that once a girl is through with her secondary level of education she is ripe for marriage and so there seems to be little or interest in furthering their education. It could also be due to lack of financial resources to further their education. The reason why the women are disadvantaged in resource accessibility could be due to gender inequality and the patriarchal system of inheritance that exists in the society. This makes the women have no direct ownership to land and properties as it is believed that it is only the men that have the right to ownership of land. This in turn affects the standard of living of the women as they have to depend solely on the men for resources and this as well as affects their level of income. Since the women do not have access to ownership of land and resources it becomes difficult for them to get the necessary inputs and resources to boost their agricultural productivity as land is a primary factor in agriculture. It was also found that the poverty status of women was worse off as compared to the men and it could be as a result of lack of access to resources for agricultural production. It was also found that women were not involved in any form of decision making, both in family and in their immediate community and this could also be due to gender inequality.

\section{Conclusion}

Based on the findings of this study, it is visible that there is gender inequality in access to resources most especially land and other major resources. It is also clear that there is gender disparity in decision making as the women have no right to make decisions in their homes and immediate societies. Also the households headed by women were found to be poorer than those headed by men. It was also discovered that less women attained tertiary education as compared to the men whereby most women stopped their education after secondary level. 


\section{Recommendations}

Based on the findings of this research work, there is need to make policy recommendations which should be centered on building human capacity and improving the standard of living of both men and women and this can be achieved in the following ways:

1. Efforts should be made at building human capacity (especially women) by investing more in their education. Thus, having education that is more relevant to the technical knowledge required in agriculture and other sectors in the society will boost the living conditions of households in the study area.

2. In policy making processes concerning the rural farmers, gender sensitization should be made a key factor and the policy makers should ensure that the policies that are being made are implemented.

3. Financial services in form of credit facilities and provision of inputs even at subsidized rates should be made available to these smallholder farmers by the government and government should also ensure that these services get to the farmers and not the unintended beneficiaries.

\section{References}

Abumere SI, O Oluwasola (2001). "Food Supply to Ibadan: A Study of Rural-Urban Linkages". Development Policy Centre, Research Report No. 29, 52p.

Agbi, M.O. (2009) Poverty Alleviation Programmes in Nigeria, National Assembly Legislative Digest, Vol 2, A Publication of the National Assembly.

Ajani, O.I.Y (2008) Gender Dimensions of Agriculture, Poverty, Nutrition and Food Security in Nigeria, Nigeria Strategy Support Program (NSSP) Background Paper No. NSSP 005.

Ajibefun IA 2002. Analysis of Policy Issues in Technical Efficiency of Small scale Farmers Using the Stochastic Frontier Production Function: With Application to Nigerian Farmers. Paper Prepared for Presentation at the International Farm Management Association Congress, Wageningen, Netherland, July, 2002.

Akinsanmi, A., W. Doppler, and C. Nwajiuba. (2005). Gender inequalities and their implications for living standard and food security among male and female- headed households in Imo State, Nigeria. Conference on International Agricultural Research for Development, October 11-13, Tropentag, Stuttgart-Hohenheim.

Alayande B and O. Alayande (2004). A quantitative and qualitative assessment of vulnerability to poverty in Nigeria. Being paper submitted for presentation of CSAE Conference on poverty reduction, growth and human development in Africa, March, 2004.

Anyanwu, J.C (2010) Poverty in Nigeria: A Gendered Analysis, Journal Statistique Africain Numero 1, pp 39-40.

Apata T.G, Apata O.M, Igalajobi O.A, Awoniyi S.M.O (2010) Determinants of Rural Poverty in Nigeria: Evidence from Small Holder Farmers In South- Western, Nigeria. Journal of Science and Technology Education Research Vol 1(4), pp 85-91.

Asogwa B.C., Umeh J.C., Okwoche, V.A. (2012) Poverty and Efficiency among the Farming Households in Nigeria: A Guide for Poverty Reduction Policy, Current Research Journal of Economic Theory 4(1), pp 6-10.

Ayoola GB, Aina B, Mamman, Nweze N, Odebiyi T, Okunmadewa F, Shehu D, Williams O, Zasha J (2000). Nigeria: Voice of the Poor; Country Synthesis Report World Bank.

Chianu, J.N and H. Tsuji. 2004. Missing link in sustainable food production in West Africa: Case of the savannas of northern Nigeria. Sustainable Development 12:212-222.

Collier P. and S. Dercon (2009), "African Agriculture in 50 Years: Smallholders in a Rapidly Changing World?" A paper presented at the FAO Expert Meeting on How to Feed the World in 2050, Rome, Food and Agriculture Organization.

El-Laithy H. (2008) The Gender Dimension of Poverty in E gypt ERF Working Paper 0127, pp 6-7.

FGN (2005). Poverty Profile for Nigeria. National Bureau of Statistics.

FGN (2007). Nigeria Poverty Assessment 2007. The National Bureau of Statistics in Collaboration with the World Bank.

IFAD (2009) Gender Dimensions Of Agricultural And Rural Poverty: The Differentiated Pathway Out Of Poverty: Status Trends And Gaps. Published by the Food and Agricultural Organization of the United Nations, the International Fund for Agricultural Development and the International Labour Office, Rome.

Ike, P.C and V. U. Oboh (2009) A Gender Analysis of Poverty Gap among Farm Families in Ukwani Local Government Area of Delta State, Nigeria. Agricultural Journal Vol 4 (6): 254-259.

Lipton M (2005). Can Small Farms Survive, Prosper, or be the key Channel to Cut Mass Poverty? Presentation to FAO Symposiums on Agricultural Commercialization and the Small Farmer, Rome, 4-5 May. 2005.

Medeiros M., Costa J. (2008) What Do We Mean By "Feminization Of Poverty"? A One Pager Publication by the International Poverty Centre, No 58, Brazil.

Moghadam V. (2005), Globalizing Women: Transitional Feminist Network. Social and Human Sciences (SHS) Papers in Women's Studies / Gender Research Work, No 2, pp 4-6, 13-23.

National Bureau of Statistics (NBS) (2009). (www.nigerianstat.gov.ng)

Obisesan A.A. (2013) Credit Accessibility and Poverty among Smallholder Cassava Farming Households in Southwest, Nigeria, Greener Journal of Agricultural Sciences Vol. 3(2), pp 120-127. 
Okorie, U. (2013) Women Education in Nigeria: Problems and Implications for Family Role and Stability, European Scientific Journal vol.9, No.28 pp1-11.

Okunmadewa F (2002). Poverty and Agricultural Sector. Poverty reduction and the Agricultural sector in Nigeria, edited by Foluso Okunmadewa, Elshaddai Global Ventures Ltd. Ibadan, Nigeria.

Okunmadewa, FY, Yusuf SA, Omonona BT (2005). Social Capital And Poverty Reduction In Nigeria, Revised Report Submitted To Africa Economic Research Consortium (AERC) Nairobi, Kenya.

Oniang'O, R. and E. Mukudi. 2002. Nutrition and gender in nutrition: A foundation for development. http://www.unsystem.org/SCN/ Publications/foundation4dev/foundation4dev.htm.

Poulton C, Dorward A, Kydd J (2005). The Future of Small Farms: New Directions for Services, Institutions and Intermediation. In Proceedings of Research Workshop on the future of small farms Wye, UK Organised by International Food policy research institute (IFPRI)/2020 initiative and Overseas Development Institute (ODI) Imperial College, London.

Rahman, S.A. (2008). Women's involvement in agriculture in northern and southern Kaduna State, Nigeria. Journal of Gender Studies 17 (1): 17-26.

Spencer, D. (2002). The future of Agriculture in Sub-Saharan Africa and South Asia. In Sustainable Food Security for All by 2020. Proceedings of an International Conference, September 4-6, 2001, Bonn, Germany. International Food Policy Research Institute, Washington, D.C.

Spieldoch, A. (2007). A row to hoe. The gender impact of trade liberalization on our food system, agricultural markets and women's human rights. Institute for Agriculture and Trade Policy (IAIP)/ International. Gender and Trade Network (IGTN): Friedrich- EbertStiftung Geneva, Switzerland.

Ukoha, O. O and Nsikakaba, Etimi, A, (2010) Analysis of Poverty Profile Of Rural Households: Evidence From South-South Nigeria. Journal of Agriculture and Social Sciences Vol 6, No 3 pp 48-52.

World Bank (1986) Poverty and Hunger: Issues and Options for Food Security in Developing Countries. Washington, D. C., USA. 